\title{
Disseminated Kaposi sarcoma in newly diagnosed HIV
}

\author{
C. Wagner $\cdot$ B. Preiswerk $\cdot$ R. Weber
}

Received: 21 December 2010/Accepted: 12 January 2011/Published online: 4 February 2011

(C) Urban \& Vogel 2011
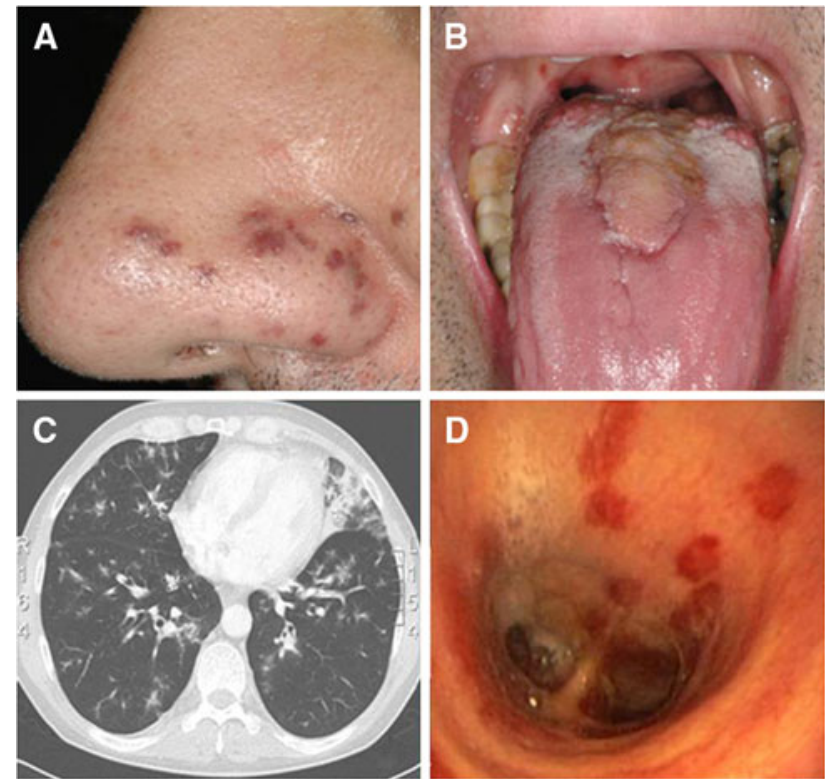

Fig. 1 a Cutaneous Kaposi lesions. b Kaposi lesions of the tongue and oropharynx. c Computed tomography (CT) chest scan showing pulmonary Kaposi infiltrates. d Pathognomonic Kaposi's lesions of the bronchial system

C. Wagner $(\bowtie)$

Department of Internal Medicine, University Hospital Zurich, Rämistrasse 100, 8091 Zurich, Switzerland

e-mail: claudia.wagner@usz.ch

B. Preiswerk - R. Weber

Department of Infectious Disease, University Hospital Zurich, Rämistrasse 100, 8091 Zurich, Switzerland

e-mail: benjamin.preiswerk@usz.ch

R. Weber

e-mail: rainer.weber@usz.ch
A 45-year-old Swiss commercial clerk consulted his GP with progressive dyspnoea at exertion. Clinical examination revealed multiple raised purple plaques on the face and extremities (Fig. 1a) and multiple round, livid lesions of the tongue and oropharynx (Fig. 1b). Sexual history was significant for multiple prior homosexual partners. No personal history. A chest computed tomography (CT) scan showed multiple pulmonary infiltrates and mediastinal lymphadenopathia (Fig. 1c). HIV screening was positive. Tubercle bacilli tested negative in three sputa by direct microscopy. A bronchoscopy was performed, revealing typical Kaposi's lesions in the upper and lower respiratory tract (Fig. 1d). The patient's CD4 cell count was 143/ $\mu$ l. HIV viral load and HHV-8 viral load in plasma was $135,028 \mathrm{k} / \mathrm{ml}$ and $1,565 \mathrm{k} / \mathrm{ml}$, respectively. The patient was started on antiretroviral treatment with ritonavir-boosted atazanavir, emtricitabine and tenofovir. Ten days later, the patient was re-admitted to the hospital due to progressive dyspnoea. Clinical examination revealed progression of the oral Kaposi lesions. Arterial blood gas analysis confirmed severe partial respiratory insufficiency (arterial partial pressure of oxygen $\left[\mathrm{paO}_{2}\right]=6 \mathrm{kPa}$ breathing ambient air). CT chest scanning showed radiological progression of pulmonary infiltrates. Chemotherapy with doxorubicin $20 \mathrm{mg} / \mathrm{m}^{2}$ body surface area on a 2 -weekly schedule was started. Surgical resection of the oropharyngeal Kaposi lesions was performed. Respiratory function readily improved upon treatment. The patient's symptoms steadily improved from the first cycle of doxorubicin. Staging CT scanning will be performed after six cycles of chemotherapy.

We report this case to illustrate the diverse clinical features of disseminated Kaposi's sarcoma in an HIVpositive late presenter.

Conflict of interest The authors declare no conflict of interest. 